\title{
Feasibility of Nano-based Neuroprosthetics in Neurosurgery
}

\section{Viabilidade de neuropróteses nanotecnológicas em neurocirugia}

\author{
Arthur Saniotis ${ }^{1,2}$ \\ Maciej Henneberg 2,3 Abdul-Rahman Sawalma ${ }^{4}$
}

Address for correspondence Dr. Arthur Saniotis, PhD, Department of Medical Laboratory Science, Knowledge University, Kurdistan Region, Iraq (e-mail: arthur.saniotis@knu.edu.iq).
Since their development, auditory, visual and pain-reducing neuroprosthetic devices have improved the lives of thousands of patients. Further advances in motor neuroprosthetics are attempting to restore motor functions in tetraplegic, limb loss and brain stem stroke paralysis subjects. This has been clinically feasible by simulating the conditions by which neuroplasticity is triggered. ${ }^{1}$

While the use of nanotechnology in neurosurgery is still at a developmental stage, over the next few decades medicine will witness an influx of nanotechnology techniques to neurosurgery in the areas of management, detection and treatment of gliomas, oncology, neuromodulation, neuroregeneration, ${ }^{2}$ and minimally-invasive diagnostic and neurosurgical techniques. ${ }^{3,4}$ For example, future neurosurgical procedures may use laser beams to seal tissue via the use of specific gold nanorods (GNRs), which would significantly minimize vascular injury and decrease postoperative healing time. $^{3}$

The advent of nanotechnology in neurosurgery will challenge the current mechanistic approach that informs neuroprosthetics, through which it is not possible to apprehend the complexity of the cortical processes involved in cognitive, motor and sensory functions. One reason for this is our insufficient knowledge of the evolutionary processes that have shaped the human cerebrum. ${ }^{5}$

Second, current neuroprosthetic devices have a range of postoperative problems that include inflammation, glial-cell necrosis and scarring, ${ }^{6}$ as well as degradation of electrode implants, among other problems. These are well-known to every neurosurgeon. Additionally, even the type of implantation method used by neurosurgeons, ${ }^{7}$ as well as the time it takes to insert a neuroprosthetic device, can reduce their efficiency. ${ }^{8}$

Recently, we published an article ${ }^{9}$ in Frontiers in Neuroscience in which we developed an idea for a novel nanotech neuroprosthetic device called "endomyccorhizae-like interface" (ELI). One reason for the development of ELI was to bypass the aforementioned neurosurgical problems. ${ }^{9}$ Our design for ELI was inspired by endomyccorhizae (fungus/plant root symbiosis). During this process, fungi bundles project finger-like extensions (mycelium) that penetrate plant roots, forming a branching matrix (arbuscules). Similarly, in theory, ELI would send out multiple mesh fibers from a cation chamber. Briefly, the fiber tips would then attach to specific axonal membranes, thus achieving connectivity. ${ }^{9}$ ELI's role would be in transmitting action potentials between neurons to which it is connected, as well as in improving the speed of receiving action potentials. In other words, ELI would endeavor to partially regain the normal connectivity speeds in interrupted neural pathways (that is, those evident in neurodegenerative disorders) without altering the regular tasks of neurons. ${ }^{9}$ Uninhibited increase in neuronal activity may lead to functional difficulties. Therefore, ELI or other future nano-based neuroprosthetic devices will need to be received

June 24, 2019

accepted

September 30, 2019
DOI https://doi.org/

10.1055/s-0039-3399535. ISSN 0103-5355.
Copyright $\odot 2020$ by Thieme Revinter Publicações Ltda, Rio de Janeiro, Brazil
License terms

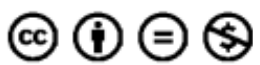


able to react to inhibitory signals, thereby enhancing their sensitivity to signaling.

The ELI device would be delivered using a fine syringe needle through the orbital roof, which is lined with meninges, and inserted $\sim 1 \mathrm{~mm}$ into the subarachnoid space with the cerebrospinal fluid (CSF). ${ }^{9}$ The micro-diameter of the needle would ensure minimal invasiveness. Recently, researchers have used syringe needles with a diameter of $100 \mu \mathrm{m}$ when injecting implanted electrical meshes into the brains of anaesthetized mice. ${ }^{10}$

Hence, this type of delivery would avoid the problems of injecting nanoparticles into the blood-brain barrier. The ELI would move using a propeller-like device. Upon entering the subarachnoid space, ELI would be in proximity with the cortical surface, and would spread over the neocortex by sensing the electrical activity of neurons. The energy to power ELI could be obtained from adenosine triphosphate (ATP) ${ }^{11}$ or brain-cell (neurons and glial cells) electrolytes. ${ }^{12}$

We envisage that the quantification of the cognitive improvements achieved by patients could be made by measurements of mental aptitude with an appropriate test such as the IQ test or modified psychometric tests, based on recommendations by Snow et $\mathrm{al}^{13}$ and Ferrara. ${ }^{14}$ The tests would encompass a wide-ranging structure to assess not only the mental processes in patients (numerical/verbal/diagrammatic reasoning, tests for explicit/implicit memory), but also the interaction between patient and task in various situations and environments, as well as the response and reaction performance during kinesiology tasks to assess neural control in various clinical contexts. ${ }^{14,15}$ Performance results would be recorded in computer-based formats, enabling scientists to deduce the novel context exploration (NCE)/neuron interaction in individuals. ${ }^{14}$ Comprehensive testing would be ongoing to determine the long-term effects of NCEs.

While ELI is at a developmental stage, it exemplifies how nanotechnology may be able to significantly reduce the problems of current neuroprosthetic devices. A great deal of work is needed before ELI or other nano-based neural devices are engineered and become part of neurosurgery. The feasibility of such neuroprosthetics will require an understanding of the dynamics of diffuse neural networks and their integrative faculties.

The feasibility of using ELI seems obvious in neurodegenerative disorders that slow down, or interrupt, the communication among neurons. The device may also become useful in cases of recovery from strokes, brain injuries or therapeutic removal of a part of the cortex, when tumors are excised, for example. In those cases, it is necessary for uninjured cortical areas to take over functions normally performed in the damaged/removed cortex, and increasing the connectivity of the remaining cortex may improve the recovery. Were ELIs be able to be made sensitive to specific neurosecretions, they might provide replacements for dysfunctional neurotransmitter systems, such as dopaminergic systems.

Conflict of Interests

The authors have no conflict of interests to declare.

\section{References}

1 Lebedev MA, Nicolelis MAL. Brain-machine interfaces: past, present and future. Trends Neurosci 2006;29(09):536-546

2 Tan A, Jeyaraj R, Ashkan K. Nanotechnology in neurosurgery: thinking small, dreaming big. Br J Neurosurg 2017;31(05): 538-550

3 El Badry A, Mattar MA. Nanotechnology in Neurosurgical Practice. EC Neurology 2017;5(04):149-171

4 Hernández-Pedro NY, Rangel-López E, Magaña-Maldonado R, et al. Application of nanoparticles on diagnosis and therapy in gliomas. BioMed Res Int 2013;2013(06):351031

5 Saniotis A, Henneberg M, Kumaratilake J, Grantham JP. “Messing with the mind": evolutionary challenges to human brain augmentation. Front Syst Neurosci 2014;8(152):152

6 Leach JB, Achyuta AK, Murthy SK. Bridging the Divide between Neuroprosthetic Design, Tissue Engineering and Neurobiology. Front Neuroeng 2010;2:18. Doi: 10.3389/neuro.16.018.2009

7 Nicolelis MA, Dimitrov D, Carmena JM, et al. Chronic, multisite, multielectrode recordings in macaque monkeys. Proc Natl Acad Sci U S A 2003;100(19):11041-11046

8 Biran R, Martin DC, Tresco PA. The brain tissue response to implanted silicon microelectrode arrays is increased when the device is tethered to the skull. J Biomed Mater Res A 2007;82(01): 169-178

9 Saniotis A, Henneberg M, Sawalma A-R. Integration of nanobots into neural circuits as a future therapy for treating neurodegenerative disorders. Front Neurosci 2018;12:153. Doi: 10.3389/ fnins.2018.00153

10 Liu J, Fu TM, Cheng Z, et al. Syringe-injectable electronics. Nat Nanotechnol 2015;10(07):629-636

11 Senthilnathan B, Bejoy J, Suruthi L, et al. Nanorobots - a hypothetical Concept of interest. Pharma Sci Monitor 2016;7(03): 70-84

12 Angle MR, Cui B, Melosh NA. Nanotechnology and neurophysiology. Curr Opin Neurobiol 2015;32(32):132-140

13 Snow RE, Corno L, Jackson D. Individual differences in affective and conative functions. In: Berliner DC, Calfee RC. (eds.), Handbook of Educational Psychology. New York: Macmillan; 1996: 243-310

14 Ferrara S. Toward a psychology of large-scale educational achievement testing: some features and capabilities. Educ Meas 2006;25:2-5

15 Jensen AM. Estimating the prevalence of use of kinesiology-style manual muscle testing: A survey of educators. Adv Integr Med 2015;2(02):96-102 